\title{
As Cartas de Amarna e as Relaçóes Internacionais no Egito do final da XVIII Dinastia
}

\author{
Liliane Cristina Coelho \\ Centro Universitário Campos de Andrade \\ Moacir Elias Santos \\ Centro Universitário Campos de Andrade
}

\section{Introdução}

Os egípcios sempre mantiveram contato com as populações de seu entorno, mas durante o Reino Novo (c. 1550-1070 a. C. $)^{1}$, período de maior expansão territorial e que ficou conhecido como Império Egípcio, tais relaçóes são melhor documentadas. No final da XVIII Dinastia, entre os últimos anos do reinado de Amenhotep III (c. 1391-1353 a. C.) e o início do período de Tutankhamon (c. 1335-1323 a. C.), a troca de correspondências entre os reis egípcios e governantes dos Estados aliados foi bastante abundante e algumas destas cartas foram localizadas na cidade de Akhetaton, capital do Egito durante o reinado de Amenhotep IV/Akhenaton (c. 1553-1335 a.C.).

O sítio de Akhetaton é conhecido desde o início do século XVIII. A primeira referência moderna à cidade é encontrada na obra do jesuíta francês Claude Sicard, que visitou o Egito em 1714, e o primeiro mapa detalhado do assentamento urbano foi publicado por Napoleáo Bonaparte na Description de l'Égypte, obra que resultou de sua expedição ao país iniciada em 1798. Entre os primeiros egiptólogos a visitarem o sítio estáo John Gardner Wilkinson, James Burton, Jean-François Champollion, Robert Hay, Nestor l'Hôte e Karl Richard Lepsius $^{2}$.

\footnotetext{
${ }^{1}$ As datas seguem a cronologia proposta por J., BAINES; J., MÁLEK, J. O mundo egípcio: deuses, templos e faraós. Madri: Ediciones del Prado, 1996. v.1. p.36.

2 T. E., PEET ; C. L., WOOLLEY. The City of Akhenaten I. Excavations of 1921-22 at el-
} 
A descoberta, em 1887, de um grupo de cartas atualmente conhecidas como Cartas de Amarna, por uma camponesa que vasculhava as ruínas da cidade em busca de materiais que pudessem ser utilizados como fertilizantes no campo (sebak, em árabe), levou às primeiras escavaçóes na cidade principal, na temporada de 1891-92, sob a direção de William Matthew Flinders Petrie. Os locais explorados pelo arqueólogo foram o templo dedicado ao Aton, o Palácio Real e algumas casas privadas ${ }^{3}$. Os resultados desta primeira temporada foram publicados na obra chamada Tell el-Amarna ${ }^{4}$, até hoje uma importante referência sobre o sítio.

A correspondência localizada pela camponesa, que corresponde a tabletes escritos em cuneiforme, na realidade é parte das cartas trocadas entre o faraó e reis de Estados da Síria-Palestina. Atualmente são conhecidos 382 tabletes, dos quais 350 são cartas ou listas que deveriam estar anexadas às cartas e os demais constam de contos ou relatos mitológicos ${ }^{5}$. A escrita utilizada é a cuneiforme, a "língua franca" do século XIV a. C. Do conjunto, apenas nove cartas foram "escritas" pelo faraó, sendo todas as outras correspondências recebidas pelos reis egípcios ${ }^{6}$.

Para este artigo, analisamos as cartas que foram enviadas ou recebidas dos Grandes Reis de Babilônia, Assíria, Mitanni, Hatti, Arsawa (Anatólia) e Alashiya (Chipre) ${ }^{7}$ e que ajudam a esclarecer como eram as relaçóes do Egito com outros Estados do Antigo Oriente Próximo no período corresponde ao final da XVIII Dinastia.

\section{As relaçóes internacionais por meio das Cartas de Amarna}

As Cartas de Amarna, junto com documentos contemporâneos ugaríticos e hititas e outras fontes egípcias, são documentos valiosos para a

Amarneh. London: The Egypt Exploration Society, 1923, p.v.

${ }^{3}$ Ibidem, p.v.

${ }^{4}$ W. M. F., PETRIE. Tell el Amarna. London: Methuen \& Co., 1894.

${ }^{5}$ W. L., MORAN. Les Lettres d'el-Amarna. Paris: Les Éditions du Cerf, 2004, p. 17.

${ }^{6}$ J., HUEHNERGARD; S., IZRE'EL. (ed.) Amarna Studies: collected writings. Winona Lake (Indiana): Eisenbrauns, 2003, p. 238.

${ }^{7}$ Ibidem, p. 238. 
história da Síria e da Palestina durante parte do século XIV a. C. ${ }^{8}$. A correspondência cobre cerca de 25 a 30 anos, entre os últimos anos de reinado de Amenhotep III e o primeiro ano de governo de Tutankhamon, sendo mais abundante durante o reinado de Akhenaton. Segundo nos informa o assiriólogo americano William Moran, que é autor da tradução mais recente dos documentos, apesar de escritas em acadiano, as cartas são fontes valiosas sobre o cananita, que tem no hebraico bíblico um de seus dialetos? ${ }^{9}$ Um desenho de linha que apresenta dois modelos destas Cartas é apresentado na figura 1.

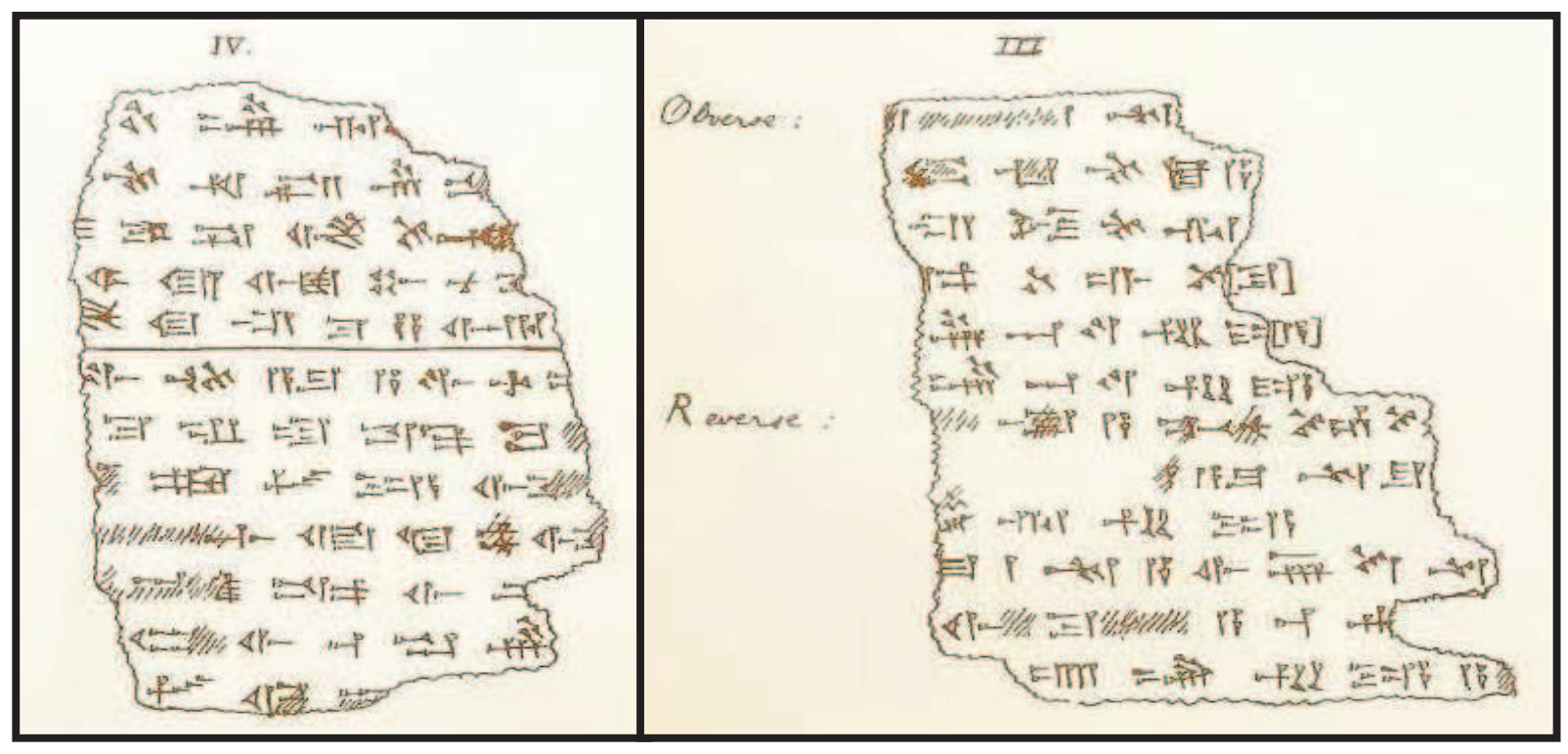

Figura 1 - Desenhos de linha, elaborados por Petrie, que mostram duas das Cartas de Amarna localizadas por sua equipe durante as escavaçóes de 1891-92. Referência: PETRIE, W. M. F.. Tell el Amarna. London: Methuen \& Co., 1894. PL XXXI.

Em 1896, Hugo Winckler, um orientalista alemão, realizou a primeira transliteração e tradução dos textos contidos nos tabletes até então conhecidos $^{10}$. Em 1907, após novas descobertas que aumentaram o número de tabletes para 358 e quando os estudos amarnianos atingiram seu auge, o assiriólogo norueguês Jorgen Alexander Knudtzon publicou o primeiro volume

\footnotetext{
${ }^{8}$ Ibidem, p. 237-238.

${ }^{9}$ Ibidem, p. 223.

${ }^{10}$ W. L., MORAN. Les Lettres d'el-Amarna. Paris: Les Éditions du Cerf, 2004, p. 15.
} 
de sua obra Die El-Amarna Tafeln, que até hoje é uma referência importante sobre as cartas e que estabeleceu a numeração ainda utilizada para sua organização ${ }^{11}$, que consta das letras $E A$ seguidas pelo número correspondente. Foi Knudtzon também quem estabeleceu, em função de diferenças nas formas de tratamento e de linguagem, a divisão das cartas em dois grandes grupos: no primeiro está a correspondência trocada com os Estados aliados (um grupo pequeno de cerca de 40 cartas) e no segundo estão as missivas enviadas ou recebidas de "vassalos" ou Estados subordinados. Os Estados aliados a que aqui nos referimos são Babilônia (EA 1-14), Assíria (EA 15-16), Mitanni (EA 17; 19-30), Hatti (EA 41-44), Alashiya (Chipre - EA 33-40) e Arzawa (Anatólia $E A$ 31-32). Já dentre os "vassalos" podemos contar pequenos reinos da SíriaPalestina que estavam sob domínio egípcio ${ }^{12}$.

Algumas das cartas enviadas por governantes de Estados "vassalos" referem-se a pedidos de ajuda ao faraó, especialmente no que se refere a tropas para evitar invasóes ou expulsar invasores. Para este trabalho, no entanto, nos interessam especificamente as cartas trocadas entre o rei do Egito e governantes de Estados aliados. Os assuntos tratados são os mais diversos, mas o cabeçalho das cartas tem uma forma geral: "Diga a X. Assim disse Y." ${ }^{3}$. A forma de tratamento mais comumente utilizada é "meu irmão" e há saudaçóes que remetem à família e aos bens do governante em questão, conforme podemos apreender a partir da saudação da carta $E A 1$ transcrita abaixo:

Diga a Kadashman-Enlil, rei de Kardunishe, meu irmão: Assim (disse) Nibmuarea $^{14}$, grande rei, rei do Egito, teu irmáo. Para mim, tudo está bem. Para ti, que tudo esteja bem. Para tua casa, para tuas mulheres, para teus filhos, teus Grandes, teus cavalos, teus carros, para o teu país, que tudo esteja muito bem. Para mim, tudo está bem. Para minha casa, para minhas mulheres, para meus filhos, meus Grandes, meus cavalos, meus carros, (e) as numerosas tropas, tudo está bem, e no meu país tudo está bem ${ }^{15}$.

\footnotetext{
${ }^{11}$ Ibidem, p. 15.

12 Ibidem, p. 18-19.

${ }^{13}$ Ibidem, p. 28.

${ }^{14}$ Nibmuarea (Nebmaatra, “o Senhor da Verdade é Ra”) é o prenome de Amenhotep III.

${ }^{15}$ W. L., MORAN. Les Lettres d'el-Amarna. Paris: Les Éditions du Cerf, 2004, p. 59.
} 
Os assuntos mais recorrentes nas missivas são as declarações de amizade, ou a manutenção de relaçóes diplomáticas provenientes de reinados anteriores; a discussão das listas de presentes relacionadas a tal amizade; os pedidos de casamento, ou os casamentos diplomáticos; e os presentes trocados no momento da união ${ }^{16}$. Com menos frequência, há pedidos de ouro ao rei egípcio e também cartas cujo objetivo é informar a vitória sobre um inimigo comum.

Durante o reinado de Amenhotep III (c. 1391-1353 a. C.), o controle egípcio sobre a Síria-Palestina estava dividido em três áreas: a região que inclui os modernos Israel, Palestina, Jordânia e a costa libanesa até Beirute, conhecida como "Canaâ", que era controlada pelo governador de Gaza; a região do atual Líbano, que tinha como responsável o governador de Kumidu; e a regiáo de Simurru (na Síria), área também conhecida como Amurru e que corresponde às terras ao norte de Ugarit, cujo responsável era o governador de Simurru ${ }^{17}$. Durante o Período de Amarna, no entanto, a hegemonia egípcia na região da Síria-Palestina foi quebrada. O crescimento militar de Estados aliados como a Assíria e o Hatti foi negligenciado pelos últimos faraós da XVIII Dinastia ${ }^{18}$. Tal afirmativa pode ser confirmada ao analisarmos a missiva $E A 41$, na qual fica clara a insatisfaçáo do rei do Hatti com o novo governo egípcio:

[Assim (diz) o Sol], Shuppiluliuma, g[rande] rei, [rei do Hatti]. Diga a Hurey $\left[\mathrm{a}^{19}\right.$, o rei do Eg]ito, meu irmão: (...) Agora, meu irmão, [t] u estás no trono de teu pai, e, assim como teu pai e eu estávamos interessados na paz entre nós, assim agora tu e eu deveríamos ter amizade um pelo outro. $\mathrm{O}$ desejo <que> eu expressei a teu pai, eu expresso a meu irmáo também. Ajudemo-nos um ao outro ${ }^{20}$.

\footnotetext{
${ }^{16}$ Ibidem, p. 33.

17 D. P., SILVERMAN; J. W., WEGNER; J. H., WEGNER. Akhenaten and Tutankhamon: revolution and restoration. Philadelphia: University of Pennsylvania Museum of Archaeology and Antropology, 2006, p. 153.

${ }^{18}$ J., HUEHNERGARD; S., IZRE'EL. (ed.) Op. cit., p. 223-224.

${ }^{19}$ Hureya é um apelido "carinhoso" de Akhenaton ou de Tutankhamon.

${ }^{20}$ W. L., MORAN. Op. cit., p. 210-211.
} 
Já na carta $E A 17$ há uma menção a uma vitória de Mitanni sobre os hititas, o que comprova o crescimento do Estado aliado:

[O mais tardar $\mathrm{n}] \mathrm{o}$ ano seguinte, no entanto, ... de meu irmão toda a terra do Hatti. Quando o inimigo se aproximava do [meu] país, Tesshup, meu Senhor, deu-lhe em meu poder, e eu venci. Não há um que retor[nou] ao seu próprio país ${ }^{21}$.

Tais cartas confirmam a importância do Egito como um grande Estado no cenário do Antigo Oriente Próximo durante o século XIV a. C. ao mesmo tempo em que mostram a insatisfação dos governantes dos Estado aliados com o governo de Amenhotep IV/ Akhenaton ou de Tutankhamon, que pareciam não se importar com a manutenção das alianças estabelecidas por seus antecessores, se levarmos em consideração principalmente a missiva $E A 41$, parcialmente transcrita acima. Em alguns casos, como por exemplo no do Hatti, a relação que se rompeu durante este período só foi restabelecida cerca de um século depois, por meio de um casamento diplomático entre o faraó Ramsés II e uma princesa hitita.

Os casamentos diplomáticos, não obstante, são um dos outros assuntos bastante recorrentes nas cartas. Significativo neste sentido é conjunto de correspondências trocadas entre o faraó Amenhotep III e o rei babilônico Kadashman-Enlil. Em cinco missivas os governantes discutem a questão do casamento, que é colocado de diferentes maneiras pelos governantes. $\mathrm{Na}$ primeira carta $(E A 1)$, enviada pelo faraó ao rei babilônico, Amenhotep III responde a Kadashman-Enlil uma questão colocada em uma correspondência anterior, infelizmente não localizada:

Diga a Kadashman-Enlil, rei de Kardunishe, meu irmão: Assim (fala) Nibmuarea, grande rei, rei do Egito, seu irmão. (...) "Você me pede agora a minha filha em casamento, mas minha irmã que meu pai lhe deu está lá, com você, e ninguém a viu (de maneira a saber) se ela atualmente está viva ou se ela está morta." Essas são tuas palavras que tu me escreveste sobre o tablete. Mas tu já enviaste aqui um homem importante que conheça a tua irmã, que poderia falar com ela e identificá-la? ${ }^{22}$

${ }^{21}$ Ibidem, p. 110-111.

${ }^{22}$ Ibidem, p. 59. 
Enquanto o rei babilônico reclama não ter notícias de sua irmã, o faraó se defende dizendo que ele deveria mandar então alguém que a conhecesse e que pudesse identificá-la, pois apenas dessa maneira poderia confirmar que ela continuava viva. A reclamação de Kadashman-Enlil, no entanto, é bem fundamentada, pois se uma irmã sua já havia sido dada em casamento ao faraó, por que ele haveria de querer também uma filha sua para o mesmo fim? A relação entre os governantes, no entanto, é mantida e em outra carta (EA 3) vemos que, apesar da desconfiança inicial, o rei babilônico deu sua filha em casamento a Amenhotep III:

\begin{abstract}
Quanto à moça, minha filha, sobre a qual você escreveu para mim para um casamento, ela se tornou uma mulher; está pronta para casar. Simplesmente envia uma delegação para buscá-la. Anteriormente, meu pai te mandou um mensageiro, e tu náo o mantiveste por um longo tempo. Tu o mandaste embora rapidamente, e tu também enviaste aqui, ao meu pai, um presente em sua homenagem ${ }^{23}$.
\end{abstract}

Os casamentos diplomáticos incluíam também a troca de presentes, aqui chamados de "presente em sua homenagem". Entre as cartas há várias listas que tratam especificamente deste assunto, como a que encontramos em $E A$ 14, que trata do envio de "presentes" em homenagem ao rei babilônico Burna-Buriyash, quando este lhe enviou sua filha em casamento. Trata-se de uma longa lista, na qual aparecem itens como peças de ouro, de cobre, de bronze, estatuetas femininas, e recipientes dos mais variados tipos.

Em outra carta (EA 4), Kadashman-Enlil questiona Amenhotep III sobre uma resposta dada a ele a respeito de seu pedido para se casar com uma das filhas do faraó. Segundo o rei babilônico, um rei pode fazer o que quiser, sem que ninguém possa falar nada sobre suas decisóes:

Além disso, meu irmão, quando te escrevi a propósito de meu casamento com tua filha, de acordo com teu hábito de não dar (uma filha), tu me escreveste nestes termos: "Historicamente, nenhuma filha de um rei do

${ }^{23}$ Ibidem, p. 66. 
Eg[ito] é dada a quem quer que seja." Por que n[ão]? Tu és é um rei, tu fazes o que gosta. Se tu deres uma menina, quem teria qualquer coisa a dizer? ${ }^{24}$

O questionamento de Kadashman-Enlil é pertinente, já que o faraó não explica os motivos que o levam a não dar uma filha em casamento, conforme o rei babilônico deixa claro em sua missiva. Amenhotep III diz apenas que se trata de um costume egípcio, o que leva o governante estrangeiro a afirmar, em outro momento na mesma carta, que se o faraó mandasse qualquer moça bonita dizendo ser sua filha todos acreditariam e ele não precisaria dar explicação alguma.

Para Samuel A. Méier, especialista em temas relacionados ao Antigo Testamento bíblico, os casamentos diplomáticos eram importantes para a manutenção das alianças entre Estados ${ }^{25}$, o que leva a uma discussão sobre quais as consequências de um rei egípcio não enviar sua filha para se casar com um rei estrangeiro. $\mathrm{O}$ autor afirma que, talvez, a troca de princesas náo tivesse necessariamente o mesmo significado para todos os atores internacionais e, por isso, tal fato náo levava a quebras nas relaçóes entre o Egito e os outros Estados da Síria-Palestina. A troca de princesas por presentes, por exemplo, poderia ser uma alternativa para este impasse.

Mençôes a casamentos anteriores de princesas estrangeiras com reis egípcios também são encontradas nas cartas. Em $E A$ 29, por exemplo, uma princesa do Mitanni é citada na troca de correspondências entre Amenhotep IV e Tushratta:

[Diga Naphurereya26, rei do Egito, m] eu irmão, meu filho, [eu] amo e que me a[ma: Mensagem de Tushratta], grande [rei], re[i de Mitann]i, teu irmão, teu padrasto, que o ama. (...) Para Tadu-Heba, minha filha, que tudo esteja bem ${ }^{27}$.

\footnotetext{
${ }^{24}$ Ibidem, p. 68.

${ }^{25}$ S. A., MEIER. Diplomacy and internacional marriages. In: R., COHEN; R., WESTBROOK, R. (ed.) Amarna Diplomacy: the beginnings of internacional relations. Baltimore: The John Hopkins University Press, 2000, p. 170.

${ }^{26}$ Naphurereya (Neferkheperura, "Belo em suas formas é Ra”) é o prenome de Amenhotep IV.

${ }^{27}$ W. L., MORAN. Op. cit., p. 179.
} 
Em outro trecho desta missiva o rei babilônico procura confirmar os laços de amizade estabelecidos desde o reinado de seu avô, Artatama, com os governantes egípcios. Ele se refere, quando menciona a correspondência constante entre ele e Amenhotep III, à rainha Tye, esposa de Amenhotep III e mãe de Akhenaton, que ele diz saber muito bem da situação a que ele faz referência. Tushratta menciona o fato de Tye ser a esposa principal e preferida de Amenhotep III e, por isso, conhecedora da política externa praticada por seu marido, o que faz da rainha uma mulher muito importante naquele contexto. Como não há uma resposta de Akhenaton que possa ser analisada, ficamos na dúvida sobre ser esta uma declaração unilateral ou recíproca de amizade.

Por fim, resta-nos falar justamente sobre as declaraçóes recíprocas de amizade. Este é o tema da carta EA 9, com certeza direcionada a Tutankhamon pelo rei babilônico Burna-Buriyash:

Diga a um Nibhurrereya28, o rei do Eg[ito], meu [irmão]: Assim (diz) Burra-Buriyas rei de Karaduniyas teu irmão: Para mim está tudo bem. Para ti, para tua casa, tuas mulheres, teus filhos, teu país, teus Grandes, teus cavalos, teus carros, que todos estejam muito bem.

A partir do momento (em que) meus ancestrais e teus ancestrais fizeram uma declaraçáo de amizade mútua, eles têm enviado belos presentes como homenagem e nunca recusaram um pedido de qualquer coisa de belo. Meu irmão frequentemente enviava duas minas de ouro como presente de homenagem. Agora, se o ouro é abundante, envie-me tanto quanto os teus antepassados, mas se é raro, envie-me metade do que teus antepassados enviavam $^{29}$.

Vemos, assim, que a manutenção das relaçóes de amizade entre o Egito e os Estados aliados passava não apenas pelos casamentos diplomáticos, tal como discutido anteriormente, mas também pela troca de presentes. $\mathrm{Na}$ carta $E A$ 9, parcialmente transcrita acima, o pedido é por uma quantidade de ouro semelhante àquela que era enviada pelos governantes anteriores. Em outros casos, como em $E A$ 3, cujo tema principal é o casamento, o ouro é

28 Nibhurrereya (Nebkheperura, “o Senhor das transformaçôes é Ra”) é o prenome de Tutankhamon.

${ }^{29}$ W. L., MORAN. Op. cit., p. 80-81. 
também o desejo do rei estrangeiro, mas este não usa como argumento a manutenção da amizade, como em EA 9: o ouro é necessário para que ele possa terminar de construir seu novo palácio. De uma maneira ou de outra, no entanto, a manutenção das relaçóes internacionais passa pelos presentes, que são também dados em troca das princesas estrangeiras.

\section{Consideraçóes finais}

Embora formem um corpus pequeno de documentação sobre a situação política da região da Síria-Palestina durante o final da XVIII Dinastia, as Cartas de Amarna auxiliam para a compreensão de como o Estado egípcio mantinha seus domínios em sua época de maior expansão territorial. Não sabemos ao certo a quantidade de tabletes que se perdeu, dada sua fragilidade e a maneira como foram descobertos - segundo alguns relatos por uma camponesa que vasculhava as ruínas em busca de fertilizante agrícola -, mas os documentos existentes mostram que tal hegemonia se conservava por meio de diferentes fatores, como os casamentos diplomáticos e a troca de presentes.

Fica claro, por meio de tais documentos, que a diplomacia era essencial para manter os territórios e os aliados conquistados por meio de guerras e, consequentemente, para manter o Império Egípcio. A instabilidade do final da XVIII Dinastia, época a que se referem os documentos aqui analisados, resultou na perda de alguns dos territórios aliados e subordinados que aparecem nas Cartas. Verifica-se, entáo, que durante os primeiros reinados da XIX ${ }^{a}$ Dinastia há um grande esforço, por parte do governo egípcio, para restabelecer tais contatos diplomáticos, o que se consegue, em alguns casos, bastante tardiamente na mesma dinastia.

A manutenção das relações diplomáticas egípcias passava também pela linguagem. Vemos pelas formas de tratamento utilizadas por aliados que eles se consideravam - e eram considerados pelo faraó - como iguais. Mesmo na língua original dos tabletes, o acadiano, a palavra utilizada para "rei" é a mesma quando falamos do faraó ou de um dos Grandes Reis do período. Já os "vassalos" tratavam ao faraó como um superior e este se sentia assim em relação a eles. 
A linguagem comercial - não tratada diretamente neste artigo - difere de um governante para outro. Os reis de Chipre e Ugarit, por exemplo, usam um vocabulário muito mais comercial que aquele utilizado pelos faraós, o que pode ser afirmado pela análise de outras fontes do período, que dizem mais respeito ao tema e que não foram mencionadas neste trabalho.

Por meio das Cartas de Amarna, entáo, é possível compreender o que estava ocorrendo no Egito e em seu entorno em uma época na qual o que chama mais a atenção dos estudiosos é a revolução religiosa que Akhenaton tentou levar a cabo no país dos faraós. Se levarmos em consideração as cartas encontradas, no entanto, não é verdadeiro afirmar que este faraó não estava preocupado com as relaçóes internacionais. Primeiro, porque os tabletes foram encontrados na cidade que Akhenaton mandou erigir para ser a sua nova capital - Akhetaton, e em segundo lugar porque a maioria dos tabletes localizados na chamada "Sala de Correspondência do Faraó" data justamente de seu reinado. 